July 2020. Forthcoming in Journal of Social Policy.

\title{
THE CONTINUING EFFECTS OF WELFARE REFORM ON FOOD BANK USE IN THE UK: THE ROLL-OUT OF UNIVERSAL CREDIT ${ }^{*}$
}

\section{Aaron Reeves ${ }^{\ddagger}$ and Rachel Loopstra ${ }^{\S}$}

July 13, 2020

\begin{abstract}
:
In this paper we explore whether the recent rise in food bank usage in the UK has been induced by the roll-out of Universal Credit. We bring together official statistics on the introduction of Universal Credit with data on food bank usage from the UK's largest food bank network. We test the relationship between Universal Credit and food parcel distribution using a range of causal identification strategies (such as fixed-effects model, Granger causality tests, and matching designs) and consistently find that an increase in the prevalence of Universal Credit is associated with more food parcel distribution. We also find that the relationship between Universal Credit and food parcel distribution is stronger in areas where food banks are active, suggesting food insecurity arising from Universal Credit may be hidden in places where food banks are largely unavailable. Though it is challenging to implement any large-scale change to social security, our analysis suggests systemic and persistent problems with this new system. Whilst the logic of Universal Credit is intuitively appealing, it has also proven to be unforgiving, leaving many struggling to make ends meet.
\end{abstract}

\section{INTRODUCTION}

One particularly stark manifestation of poverty is household food insecurity, defined in highincome countries as 'the uncertainty and insufficiency of food availability and access that are limited by resource constraints, and the worry or anxiety and hunger that may result from it' (Wunderlich and Norwood, 2006). Food insecurity, like poverty, exists in all high-income

\footnotetext{
${ }^{*}$ Replication materials are available here: https://github.com/asreeves/uc-foodbank

${ }^{\dagger}$ Aaron Reeves and Rachel Loopstra are joint lead authors of this article, and both contributed equally.

‡Department of Social Policy and Intervention, University of Oxford, aaron . reeves@spi . ox . ac . uk

${ }^{\S}$ Department of Nutritional Sciences, King’s College London, rachel . loopstra@kcl . ac . uk
} 
countries and, while estimates vary between contexts (FAO, 2019; Garratt, 2019) ${ }^{1}$, the rates of food insecurity have gone up in some countries in recent years. The Great Recession, which led to stagnating wages and rising food prices, explains some of this increase (Reeves et al., 2017), especially in countries such as Greece, Italy, and Latvia, where the prevalence of food insecurity rose after 2007 and then peaked in 2011 or 2012 (European Commission, 2019).

Rising food insecurity in Europe was not solely rooted in the economic crisis, however (Loopstra et al., 2015). In some places, it only began to increase after 2010, once austerity policies aimed at reducing government spending on social security systems were implemented (Hills, 2014). These reforms reflect a broader shift in the logic of welfare states over the last 40 years: reducing public expenditure by making the conditions of social security entitlements more demanding and by cutting the generosity of financial support (Timmins, 2017; Pierson, 1994). While the particular instantiations of this underlying logic of welfare are quite diverse, when countries reduce the generosity and the universality of social security systems, they strip away policies that would have made them relatively immune to rising food insecurity during periods of macroeconomic fluctuation (Loopstra et al., 2016).

The UK potentially fits this story too. The end of the recession, for example, did not coincide with a reduction in food bank usage (Loopstra et al., 2018), and, in spite of economic recovery, it has continued to climb over the past five years, rising by 73\% since 2014 (The Trussell Trust, 2019). Indeed, over this same period, the UK Government implemented numerous welfare reforms, many of which bore the hallmarks of this new logic of social security (Taylor-Gooby and Stoker, 2011). The rhetorical frames used to justify welfare reform in the 1990s re-entered the political discourse in the wake of the Great Recession (McArthur and Reeves, 2019) and were particularly prominent in the UKgovernment's 2010 Spending Review. 'Universal Credit' (UC), which was rolled-out in earnest from 2014 onwards, was the epitome of these efforts (Timmins, 2016).

This paper seeks to empirically assess whether rises in food bank usage are associated with the introduction and roll-out of Universal Credit, which, we argue, has a number of features that may increase the risk of economic hardship for some claimants. Using Trussell Trust data on food parcel distribution alongside a range of official statistics, we find that, when the UC caseload rises from one month to the next, the number of food parcels being distributed goes up too. This relationship is not constant across the UK, however. In places without a readily accessible food bank, putting more people on UC has a far smaller influence on the number of food parcels that are given out. This does not mean, we take it, that UC fails to produce deprivation in areas without food banks; rather it seems that, in these place, UC is in fact creating hidden hunger. We also explore the switch to Full-Service UC, testing whether this exacerbates or minimises the association with food bank use, finding that introducing Full Service appears to be independently related to higher food bank usage. Our results speak to broader debates about how social security is structured and how reforms which seek to activate both the employed and the unemployed may leave some worse off.

\footnotetext{
${ }^{1}$ The prevalence levels vary from $3-5 \%$ of the population in countries such as Sweden, Germany, and Denmark, to more than $10 \%$ in the UK and the United States
} 


\section{HOW UNIVERSAL CREDIT ALTERED SOCIAL SECURITY}

Drawing on the same logic informing welfare reform policies elsewhere (Kenworthy, 2010), UC has been designed to reduce welfare dependency and ensure people are financially better off when employed rather than on social security (Hills, 2014). UC expands welfare conditionality and benefit sanctions to incentivise people to improve their financial situation. Conditionality was previously reserved for those described as 'trapped' in the benefit system (e.g., out-of-work benefits) (Dwyer and Wright, 2014). Under UC, conditionalities apply to some people in-work and eligible for housing benefit or working- or child-tax credits (Hills, 2014; Timmins, 2017). Another major change introduced with UC is that payments are paid in arrears. This model is intended to mirror the world of work, where a majority of people receive their first pay cheque after a month or more of employment (Millar and Bennett, 2017). Until February 2018, the design involved a six-week wait for a benefit payment to be made. This 'assessment period' included a seven-day spell when the person was not eligible for UC, one month during which claimants' incomes were assessed, and another seven days for processing the claim payment. From February 2018, this waiting period was reduced to five weeks, but has not been further reduced.

UC also innovates in important ways. It creates a new infrastructure for social security by combining out-of-work support, housing benefits, and tax credits into one system (Timmins, 2016; DWP, 2010). Combining these benefits into a single application and payment system is intended to enable people to move between out-of-work and in-work benefits more smoothly, reducing the risk of experiencing financial loss due to 'churn' into and out of the social security system as people's circumstances change (Hills, 2014). UC is also 'digital-by-default', what is called Full Service (Dwyer and Wright, 2014), allowing people to make a claim without travelling to a centralized site.

There has been a great deal of debate concerning the potential outcomes of UC. Some argue UC's labour activation components may have had positive effects on employment (Griggs and Evans, 2010; DWP, 2018), as labour activation programmes have been shown to do this elsewhere (Griggs and Evans, 2010). But a major qualitative longitudinal study based in the UK found that welfare conditionality, and in turn sanctions, are not effective at facilitating employment or in-work progression (Welfare Conditionality, 2018). In some cases, sanctions may be deducted from Housing and Child elements of UC payments, which could not happen under the separated benefit system (Webster, 2019).

Digitalizing the service may also exclude those who lack IT skills and may actually make it harder for some to submit claims (NAO, 2018). Assessment of the roll-out of the Full Service version of UC has shown that $98 \%$ of claimants were able to register their claim online (Foster et al., 2018); however, this potentially misses the many who started the process but never finished. Even among these successful claimants, around 43\% said they needed more support registering their claim (Foster et al., 2018). But by streamlining the application procedure and automatically signing recipients up for any entitlements, there may be higher uptake benefit uptake than the previous, disjointed benefit system. 
The waiting period for a first UC payment, though mirroring the world of work, may lead to financial hardship and debt for those who do not have financial savings. Government data suggest such policies are inducing financial hardship and causing many claimants to take out advance payments to carry them through to the first payment, resulting in debt (NAO, 2018; Foster et al., 2017).

Lastly, financial outcomes of UC are also mixed, as levels of entitlements are changed for some claimants under UC. Some claimants will see higher payment levels under UC (Brewer et al., 2019). But, UC will reduce entitlements for a significant number of benefit claimants, with around 3 million people seeing their incomes reduced, many of whom are already living in poverty (Barnard, 2019).

\section{WHY UNIVERSAL CREDIT MAY INCREASE FOOD INSECURITY}

Given both the negative and positive aspects of the new UC system, there is considerable debate about what impact UC is having on households' ability to meet their basic needs, including their ability to afford food (Jitendra et al., 2018; Watts and Fitzpatrick, 2018). The claimants that benefit from higher welfare payment entitlements and from moving into higher paid employment, might be at lower risk of food insecurity. However, these positive outcomes may not offset some of the immediate, and potentially prolonged, harms of the claiming process or conditionality. For example, receiving no income through the waiting period may increase risk of food insecurity, as previous research suggests that short-term monthly income shocks are associated with periods of food insecurity (Leete and Bania, 2010). Alternatively, if advance payments are accessed, debt repayments may leave households financially worse off once UC payments start, as these are automatically deducted. Both of these issues risk increasing food insecurity and food bank usage, one with immediate effect and one in the longer term.

The extension and intensification of sanctions to a broader segment of the low-income, claimant population could also lead to food insecurity. Evidence suggests that when benefit claimants are sanctioned, they are often left without sufficient financial support to meet basic needs and need to rely on informal means of providing for themselves and their families (Garthwaite, 2016; Watts and Fitzpatrick, 2018; Fitzpatrick et al., 2018), such as food banks (Loopstra et al., 2018). ${ }^{2}$ If sanctions do leave claimants without sufficient resources, as mentioned above, they can claim a hardship payment. UC, however, has now made these hardship payments repayable, with repayment required at a rate of $40 \%$ of benefit payment.

Thus, there is real risk that UC is contributing to financial hardship, and in turn, food insecurity among benefit claimants. Food insecurity rose among low-income households generally since 2004 (Loopstra et al., 2019), and preliminary evidence suggests the introduction of UC has been linked to rising food bank use (Jitendra et al., 2017). This said, while suggestive, there are reasons to be cautious about accepting this early evidence. Earlier analyses have not, for example, linked UC claimant data to food bank usage data to study the dynamic relationship

\footnotetext{
${ }^{2}$ One important change here is that in the past if you were sanctioned for more than one failure then you would face these multiple sanctions concurrently. Now, if you are subject to multiple sanctions then you face these consecutively.
} 
between UC uptake and food bank use, nor have they considered temporal effects related to initial implementation, longer term hardship, or Full Service rollout. These are all crucial dimensions of the roll-out of UC which may alter the implications for food bank usage.

In this study, we use the roll-out of UC in the UK to explore how restructuring welfare in this way may affect food bank usage. Food bank use is a critical indicator of financial hardship, as households using food banks have frequently been found to be severely food insecure and unable to meet their basic needs, including food, utility and housing costs (Clair et al., 2019). We consider whether the net-effect of UC, namely increased conditionality, harsher penalties, and payment in arrears, but also efforts to reduce the administrative burden, increases reliance on food banks. We also examine how access to food banks may modify this relationship and if the roll-out of Full Service has had an impact over and above the UC caseload. To address these questions, we accessed the administrative database from the largest food bank network in the UK, The Trussell Trust, combining their data on the monthly volume of food bank use over 2015 to 2017 with data on the monthly caseload and take-up of UC across postcode areas throughout Britain over this same period.

\section{DATA AND METHOD}

Data on food bank use are from The Trussell Trust's food bank network, the largest network of food banks in the UK. Member food banks in this network make up about $60 \%$ of food banks that operate in the UK, and collect data using a harmonised method, which are then uploaded and held centrally by The Trussell Trust. In general, food banks that are part of the Trussell Trust also operate according to a common set of procedures (Trussell Trust, 2020), including requiring that people have a referral from a frontline care professional agency, such as Citizens Advice Bureau, social services, or GP office, and providing three-days worth of food in the food parcel that is provided when referral vouchers are redeemed.

Food bank usage has been rising across the network over the last few years, rising by $73 \%$ since 2014 (The Trussell Trust, 2019). The Trussell Trust provided data on the monthly total number parcels of food distributed to households by postcode district (equivalent to a Zip code in the United States) covering 2015 to 2017. More than one food parcel could be given to the same household within a given month, but evidence suggests the majority of households do not use a food bank more than twice in a six month period (Garratt, 2017). About $4.6 \%$ of food parcels distributed in this time period could not be matched to a postcode district. A total of 2,501 postcode districts contained at least one household that received a food bank parcel over 2015 to 2017 , while 504 postcodes did not report foodbank usage.

We accessed data from the Department for Work and Pensions (DWP) on the number of households receiving UC in each postcode district available from Stat X-plore (more details on the roll-out of UC are available in Box 1 and Web Appendix 1). At the time of our analysis, data were last updated on 22nd March 2018, and we matched DWP data to the Trussell Trust data over the same period (from August 2015 to December 2017). These DWP data contain the number of households with an active UC claim. Crucially, the UC count date occurs in the 
middle of the assessment period. Thus, because UC is paid in arrears, this count covers households currently waiting on a UC payment. There were a total of 2,907 postcode districts which could be matched between the Trussell Trust data and the DWP data included in this analysis, covering households in England, Scotland, and Wales.

Box 1: The roll-out of Universal Credit

UC has been slowly introduced across the UK, both with respective to areas where it is available and the claimants it is available to. The timeline for the roll-out has been delayed a number of times. First, UC was first piloted in 12 local authority areas over September 2012 to December 2013 (DWP, 2014a). After a delay caused by concerns raised by the Major Projects Authority about UC's assessment review, the Government started rolling out UC 'live service' using in April 2013. At this time, only claimants who were single, childless, out-of-work adults without housing costs were eligible - in other words, claims that were simplest to manage. It was only extended to couples and families from April 2016. Live service did not involve online applications; instead, claimants made a claim through their local Jobcentre, as they would have done under legacy benefits. However, live service was only ever intended to be an interim service, while the Full Service was further developed. From January 2018, live service was deactivated. In areas where UC could previously be claimed through live service and where Full Service is not yet active, new claimants can now only claim legacy benefits.

From April 2016, areas began to transition to Full Service and existing live service claimants transferred onto Full Service. Of note is that all claims for UC are for claimants making a new claim. This could be because their financial situation has changed (i.e. unemployment, reduction in wages), because they've moved to a new area, or because a partner has moved in or out. Some household types are not eligible to claim due to the complexity of their cases, namely, families with three or more children. The main transition of claimants from legacy benefits onto UC was scheduled to begin in 2020 .

The phased roll out of Universal credit was not random but was implemented according to operational constraints and focused on implementation (DWP, 2014b). In web appendix 1, we provide a series of descriptive statistics showing that the roll-out was initially focused on urban areas (high population) with higher numbers of claimants (as a proportion of the working age population) but which were moderately deprived. This may introduce some bias into our analysis because the increase in the number of UC claimants was initially faster in more deprived areas (see Web Appendix 1). However, in practice, this is unlikely to influence our results because if we look at the speed at which new claimants enter UC by the period in which UC was implemented, we see very similar trends, especially in the first year (see Web Appendix 1).

We excluded data from 200 postcode districts with very small populations (less than 33 people) because these were likely to bias our results by creating large fluctuations. We also excluded non-residential postcodes. Finally, for the main parts of our analysis we only include postcode districts that are currently assigned to Jobcentre Plus administrative office (the centres which administer UC regionally), excluding a further 61 postcode districts. Our results do not vary if 
these are included in the analysis. The total number of observations included in the dataset was 76,734 referring to postcode district-months over August 2015 to December 2017 covering 2,646 postcode districts.

We also obtained data on the number of food bank distribution centres operated by Trussell Trust food banks. These refer to the physical locations where people can go to redeem their referral for a food parcel. The number of centres operating per postcode district was calculated. At the end of 2017, 1216 Trussell Trust distribution centres were operating in a total of 870 postcode districts, $30 \%$ of the sample. These data were only available for December 2017 , thus, could not be included in time-varying analyses, described in more detail below, but were included in mixed models, when fixed area characteristics could be accounted for.

Food bank use is reported as the number of food parcels distributed to households as a percentage of households in the district, and UC claimant rates are reported as percentage of households in the postcode district claiming UC.

\section{OUR ANALYTICAL STRATEGY}

We explore four issues using this data to understand how the transition and uptake of UC in postcode districts could relate to food bank use.

First, we evaluate whether in the first stage of the UC application process, encompassing the waiting period when claimants are being assessed and waiting to receive payments and also potentially other problems with the application process, is linked to food bank use. Any association between this period and food bank usage is likely to show up in the same month or the month after people come onto UC. We explore this relationship using the following linear regression model, which estimates the association between an increase in UC claimants and food bank usage:

$$
\text { Vouchers }_{i t}=\alpha+\beta_{1} U C_{i t}+\beta_{2} \text { Claimants }_{i t}+\beta_{3} \text { time }_{i t}+\beta \text { month }_{t}+\mu_{i}+\epsilon_{i t}
$$

Where $i$ is postcode district and $t$ is month. Voucher $s$ is the proportion of households receiving a food voucher in a postcode district and $U C$ is the proportion of households receiving $\mathrm{UC}$ in a given postcode district. We adjust for the proportion of the working-age population receiving Jobseeker's Allowance or claiming UC for unemployment (i.e. the new 'Claimant count' from www.nomisweb.co.uk) (Claimants) at the local authority level to account for the background level of social security dependence, which may be correlated with UC roll-out and food bank usage. Plus, we also include a linear time trend (time) and a seasonality variable (month), which is a series of dummy variables for each month of the year, to account for temporal aspects of both food bank usage and roll-out. $\mu$ is the postcode district 'fixed-effects', the differences between postcode districts that are constant over time, and $\epsilon$ is our error term. The coefficient of interest is $\beta_{1}$ : if $\beta_{1}>0$ then an increase in the proportion of households receiving $\mathrm{UC}$ is associated with the proportion of households receiving a food parcel. 
Whilst causality may be difficult to estimate in this observational setting, we estimate a number of variants of this model to test the robustness of our estimates. We estimate models with a lagged measure of the increase in UC to capture the effects in the month after their claim and also a model with a lagged measure of the dependent variable, this latter model is equivalent to a Granger causality test. ${ }^{3}$ We also use matching techniques to create a sample that is balanced on the covariates mentioned above and allow us to compare postcode districts which have introduced UC and those that have not. This focusses our analysis on only those postcode districts that are most comparable to each other (see Web Appendix 4 for full details). Consistent results across these specifications gives us more confidence in drawing causal conclusions. Standard errors are estimated at the postcode district level.

Second, we consider whether the association between UC and food bank usage is due to the difficulties of implementing a new system of welfare delivery, which may subsequently decline after UC has been active in an area for a sustained period of time. Here we add an interaction term to equation 1 between $\mathrm{UC}$ and a new variable measuring the number of months $\mathrm{UC}$ has been active in a postcode district. This interaction term tests whether $\beta_{1}$ (the association between an increase in the proportion of households receiving UC and the proportion of households receiving food vouchers) changes if UC has been active in an area for a longer period.

Third, we explore whether the total proportion of households claiming UC is associated with food parcel distribution (over and above the recent increase in the proportion of households claiming UC). Rent arrears and problematic debt have both been identified as longer-term consequences of UC; thus, if UC leave some households worse off, even after the initial waiting period has ended, we might expect food bank usage to rise with the proportion of households on UC. Here we model the proportion of households receiving a food parcel voucher using a multi-level linear regression model with random intercepts which includes two key predictors: 1) the increase in the proportion of households on UC in the last month and 2) the total proportion of households on UC one month ago. A multi-level approach allows us to include both of these variables but also allows us to simultaneously account for clustering at the level of the Jobcentre Plus Office (which may account for differences in how regional offices manage UC) and the level of the local authority (which may account for local policies that may also influence both UC and food bank usage). It also enables us to control for variables in the data set that do not change over time, namely, the number of food bank distribution centres in the postcode district, which is likely correlated with food bank usage and with the underlying level of material deprivation in an area. We also include an interaction term between the proportion of households on UC and the number of food bank distribution centres in the postcode district to test whether the association between UC and food parcel distribution varies according to the number of food distribution sites.

In the final aspect of the analysis, we test whether roll-out of Full Service UC alters any of

\footnotetext{
${ }^{3}$ A Granger causality test exploits the temporal nature of our data to test the direction of causality, namely that 'causes' typically move forward in time, that is, if event A causes event B then we would typically assume event A preceded event B. If, however, we found that event A occurred after event B then we rule out the possibility event A caused event B. A Granger causality test formalizes this institution by testing whether increases in the number of people receiving UC (event A) occurs before rises in food bank usage (event B).
} 
the relationships we estimated for the main, direct associations between rolling out UC and food bank parcel distribution. We add a binary indicator to equation 1 indicating whether Full Service is active or not and then add an interaction term between this indicator of active Full Service and the proportion of claimants on UC and whether a food bank distribution centre is present. This model tests whether increases in UC are more closely associated with food parcel distribution in areas where there is an active food bank and where Full Service has been introduced. Again, we estimate a matching model to test the consistency of our results to a more balanced sample (see Web Appendix 5 for full details). All models were estimated in STATA v 15.

\section{RESULTS}

Food bank usage has been rising in recent years. In August 2015, at the beginning of our analytic period, the median proportion of households receiving a food parcel across all postcode districts was $0.047 \%(\mathrm{IQR}=0 \%-0.17 \%)$. By December 2017, the end of our analytic period, this has risen to $0.10 \%(\mathrm{IQR}=0 \%-0.31 \%)$. While many places had no food bank usage at all, some parts of the country had seen large increases. We begin our analysis, then, with a simple question: is this rise in food bank usage in some parts of the country concentrated in areas where more people are claiming UC?

Figure 1 is a binned scatterplot of the proportion of households claiming $\mathrm{UC}$ (x-axis) and the proportion of households receiving help from food banks in October and November 2017 (y-axis). On average, there is a clear positive relationship across postcode districts. This correlation could, of course, be driven by underlying characteristics of the postcode areas, where common factors that drive people to claim UC and use food banks are causing a spurious correlation between these variables. Moreover, the common secular trend in both food bank use and UC rollout could also bias this association.

In Table 1, therefore, we report results from a series of models which explore whether this association remains after we have controlled for local area characteristics that are stable over time, the unemployment claimant rate at the local authority level, and time trends. First, we formally model the association between the change in the proportion of households receiving UC over time and the change in the proportion of households receiving food vouchers. We observe that for every 1 percentage point increase in households receiving $U C$, there is a 0.011 percentage point increase in redeemed food bank vouchers (Model 1 in Table 1). Given the average monthly percentage of vouchers redeemed per household across postcode districts in 2017 was $0.16 \%$, this change represents an increase on monthly voucher claims of about $6.9 \%$. This association is qualitatively unchanged if we estimate this association using the change in the proportion of the population receiving UC in the previous month (Model 2 in Table 1) and if we adjust for the proportion of households receiving a food parcel in the previous month (a lagged measure of the dependent variable). Model 3 in Table 1 is, in effect, a Granger Causality test and we find evidence that changes in UC 'granger cause' food parcel distribution. 
Figure 1: Binned scatterplot of the proportion of household claiming UC and households receiving help from Trussell Trust food banks across postcode districts (October and November 2017).

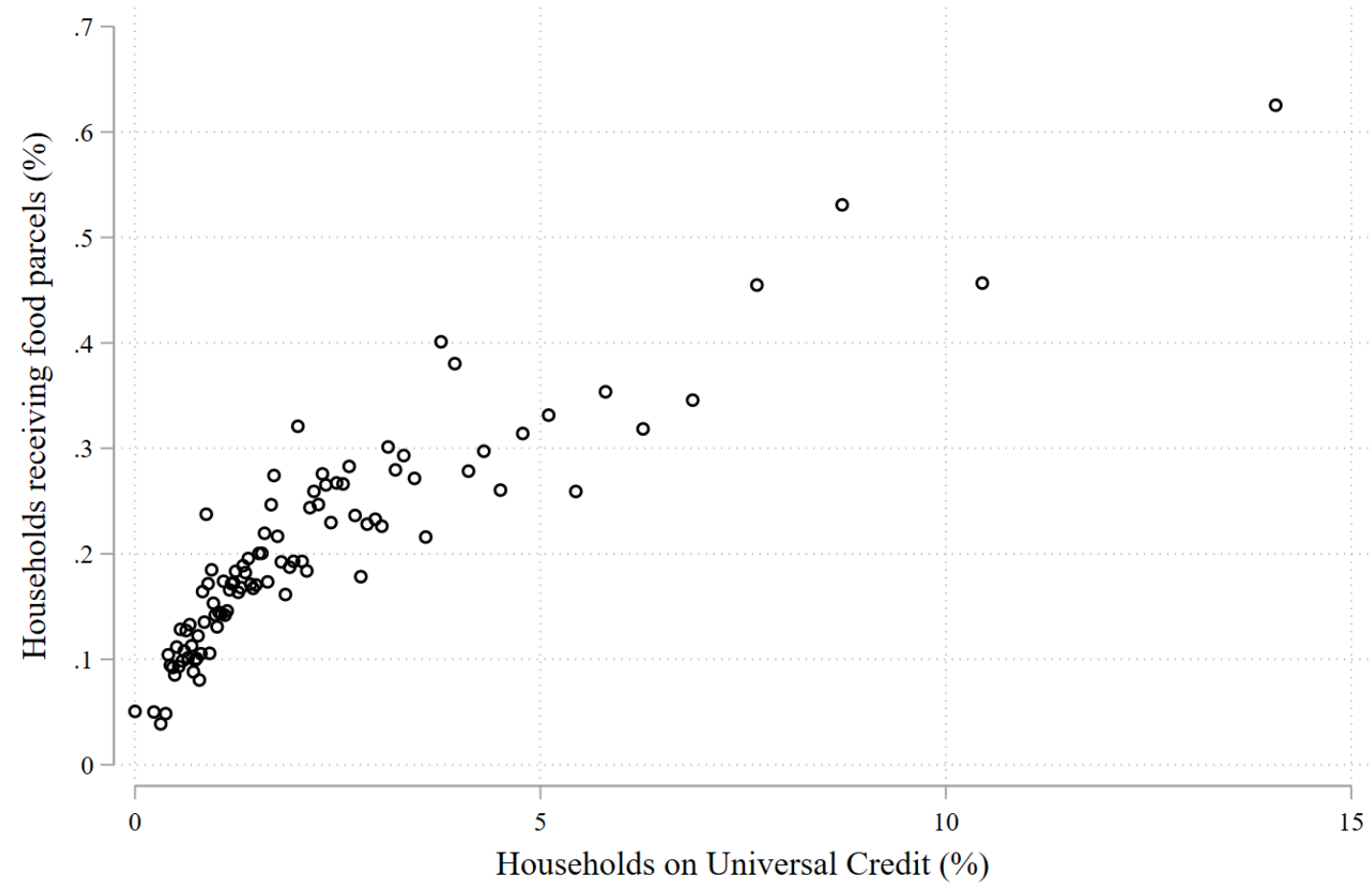

Table 1: The roll-out of UC is positively associated with the proportion of households receiving food parcels

\begin{tabular}{|c|c|c|c|}
\hline \multirow[b]{2}{*}{ Covariates } & \multicolumn{3}{|c|}{$\begin{array}{l}\text { Percentage of food bank vouchers } \\
\text { redeemed per household } \\
(95 \% \mathrm{CI})\end{array}$} \\
\hline & (1) & (2) & (3) \\
\hline $\begin{array}{l}\text { 1\%-point increase in the proportion of } \\
\text { households on UC }\end{array}$ & $\begin{array}{l}0.011^{* *} \\
(0.0018)\end{array}$ & - & 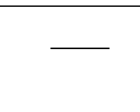 \\
\hline $\begin{array}{l}\text { 1\%-point increase in the proportion of } \\
\text { households on UC in the previous month }\end{array}$ & - & $\begin{array}{l}0.011^{* *} \\
(0.0019)\end{array}$ & $\begin{array}{l}0.0086^{* *} \\
(0.0016)\end{array}$ \\
\hline Lagged measure of food parcel distribution & $\mathrm{N}$ & $\mathrm{N}$ & $\mathrm{Y}$ \\
\hline Seasonality & $\mathrm{Y}$ & $\mathrm{Y}$ & $\mathrm{Y}$ \\
\hline Linear time trend & $\mathrm{Y}$ & $\mathrm{Y}$ & $\mathrm{Y}$ \\
\hline Observations & 76734 & 74088 & 74088 \\
\hline
\end{tabular}


Figure 2: The association between UC and food parcel distribution strengthens the longer UC has been active in an area.

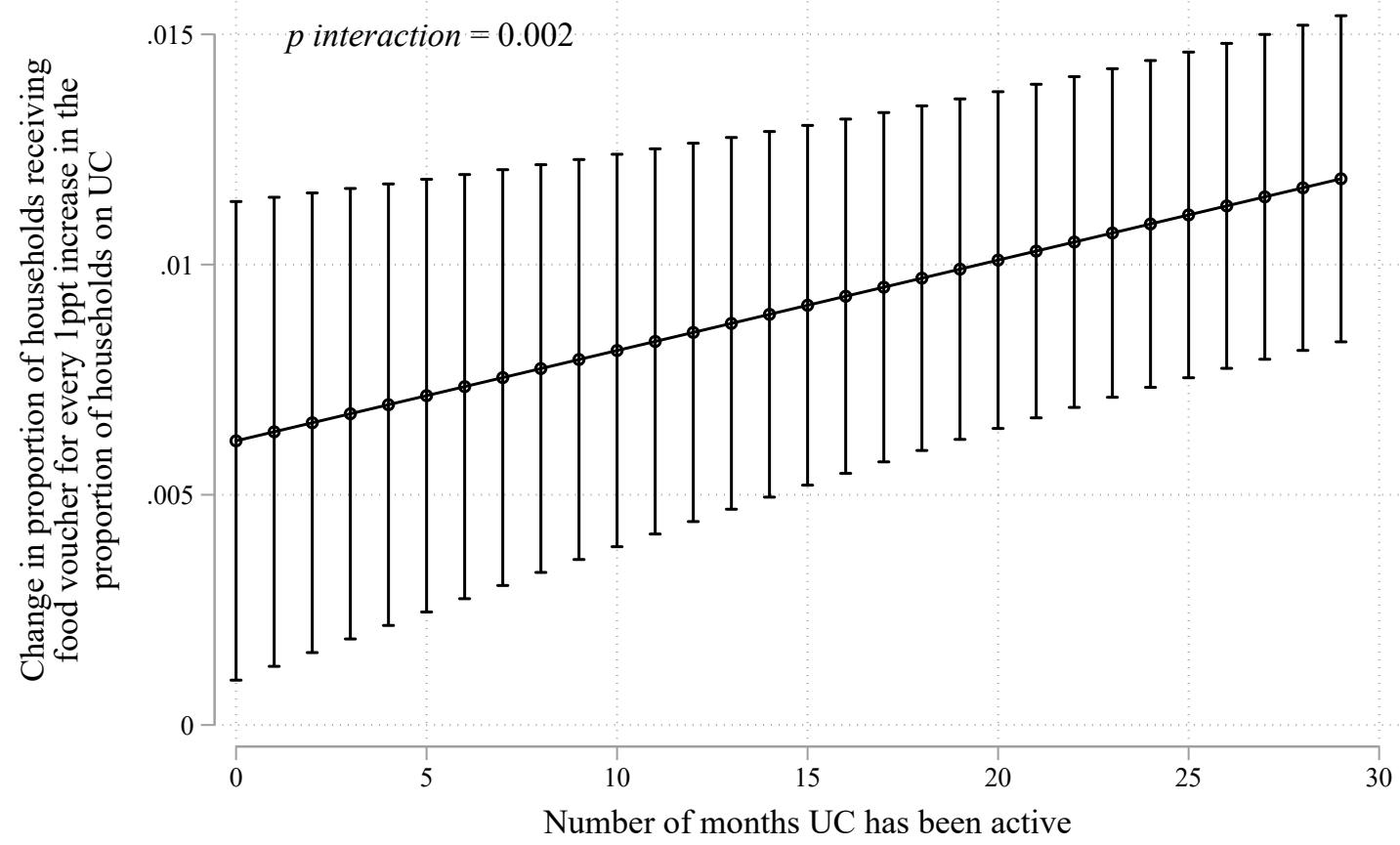

Notes: Full model is reported in Web Appendix 2. The model replicates model 1 of Table 1 except that now we include a covariate measuring the number of months UC has been active and an interaction term between the number of months UC has been active and the change in the proportion of households receiving UC.

These models suggest an acute effect of more households claiming UC on food bank use. This association could solely reflect problems with the implementation of such a 'radical' new welfare system. If this were the case, we would expect the association between the proportion of households receiving UC and receiving help from food banks to diminish with the length of time UC has been active in an area. However, if other aspects of UC, such as debt arising from the wait for payment, reductions in benefit entitlements, or sanctions applied to UC claimants, cause ongoing hardship for UC claimants, then the length of time UC was active in an area would not alter the relationship between UC claims and food bank use, or perhaps even heighten it. We test this by estimating whether the association between the proportion of household receiving $\mathrm{UC}$ and the proportion of households receiving a food parcel changes depending on how UC has been active in an area. In figure 2, we show that the longer a postcode district has actively been implementing UC, the stronger the association between the proportion of households receiving UC and the proportion of households receiving a food parcel. 
This suggests the association between UC and food bank usage is not just teething problems, but persists well after the initial introduction of the new regime in postcode areas.

Table 2: Multi-level model exploring the relationship between the level and change in households claiming UC in relation to the number of households using food banks.

\begin{tabular}{|c|c|c|}
\hline \multirow[b]{2}{*}{ Covariates } & \multicolumn{2}{|c|}{$\begin{array}{c}\text { Percentage of food bank vouchers } \\
\text { redeemed per household } \\
(95 \% \mathrm{CI})\end{array}$} \\
\hline & (1) & $(2)$ \\
\hline Per 1 percentage point increase in households $(\mathfrak{E})$ & $0.014^{* *}$ & $0.0085^{* *}$ \\
\hline claiming UC in one month prior & $(0.0022)$ & $(0.0024)$ \\
\hline Per additional 1 percentage point more & $0.014^{* *}$ & $0.012^{* *}$ \\
\hline households claiming from the month prior & $(0.00052)$ & $(0.00061)$ \\
\hline \multirow[t]{2}{*}{ Food bank in postcode district } & $0.055^{* *}$ & $0.048^{* *}$ \\
\hline & $(0.0014)$ & $(0.0017)$ \\
\hline \multirow[t]{2}{*}{ Households claiming UC X food bank present } & $\underline{-}$ & $0.028^{* *}$ \\
\hline & & $(0.0059)$ \\
\hline \multirow{2}{*}{$\begin{array}{l}\text { Change in households claiming UC X food } \\
\text { bank present }\end{array}$} & - & $0.0040^{* *}$ \\
\hline & & $(0.00074)$ \\
\hline Lagged measure of food parcel distribution & $\mathrm{Y}$ & $\mathrm{Y}$ \\
\hline Seasonality & $\mathrm{Y}$ & $\mathrm{Y}$ \\
\hline Linear time trend & $\mathrm{Y}$ & $\mathrm{Y}$ \\
\hline Region identifiers & $\mathrm{Y}$ & $\mathrm{Y}$ \\
\hline Postcode district-months & 74,088 & 74,088 \\
\hline
\end{tabular}

Notes: Standard errors are clustered for repeated observations within local authorities. Constant estimated but not reported. We estimate multi-level models with random intercepts. All models also control for population size and the proportion of the working-age population that are job-seeking benefit claimants. $\mathrm{Y}=$ model controls for that variable. ${ }^{*} p<0.05,{ }^{* *} p<0.01$

Together, these analyses suggest two mechanisms are at work. First, there is an acute effect of more households claiming UC on food bank use, which may reflect acute problems with applications and the waiting period. But it also appears that the effect of more households going on UC is only increasing the degree to which people are relying on food banks. One explanation of this relationship is that the claimant caseload is associated with the number of households receiving help from food banks, suggesting a second mechanism of persisting problems with UC, such as difficulty paying back hardship loans, rent arrears, or exposure to conditionality and sanctioning. To further explore these two mechanisms, we next use a multi-level model, which allows us to simultaneously estimate the effect of the monthly UC on-flow and the caseload on the number of food bank vouchers redeemed. We also test if we 
see a stronger relationship between UC and food bank use where food banks are present in the same postcode district.

As shown in Model 1 of Table 2, both the difference in households claiming UC from the month prior and the number households claiming UC in the month prior are independently associated with the level of food bank use. A percentage point increase in the caseload for UC increases the proportion of households receiving a food parcel by 0.014 percentage points ( $95 \%$ CI: 0.013 to 0.015$)$. Similarly, when the number of new claims increases by 1 percentage-point we see the proportion of households receiving a food parcel increase by 0.014 percentage points (95\% CI: 0.009 to 0.018 ).

Importantly, we also observe (see Model 2 in Table 2) that these relationships are stronger where food banks are located in the same postcode districts as households, suggesting that a lack of access to Trussell Trust food banks may diminish the observed relationship between UC and Trussell Trust food bank use. We visualise this model in Figure 3. Where food banks are located in the postcode district, a 1 percentage point increase in the proportion of households on UC is associated with a 0.036 percentage point increase (95\% CI: 0.026 to 0.047 ) in the proportion of households receiving a food parcel. There is also stronger relationship between the level of UC claimants and food bank use where food banks are present in the postcode district.

How do these numbers translate into the number of times people are helped by Trussell Trust food banks (see Web Appendix 3)? To do this, we calculate the same model but with a different dependent variable to more accurately calculate the absolute numbers of those affected. We see that if the total number of households on UC increases by 100, there are about 3.5 more people who receive help from food banks. When the number of households on UC increases by 100 compared to the previous month, there is a corresponding increase of about 1.3 more people who receive help from the food bank. However, as above, relationships were stronger where food banks were located in the same postcode districts. For every additional 100 household claiming UC from the month before, the level of people receiving help from food banks was predicted to rise by 6.27 (4.57 to 7.97), and for every household claiming UC in the month prior, the number of people helped was predicted to be 1.75 higher (1.58 to 1.91).

We can use these numbers to estimate the extent to which UC may have contributed to rising food bank usage in The Trussell Trust Network. To do this, we look at the month of November 2017. We choose this month because it is towards the end of the data collection period, but avoids December, when food bank use is higher than on average. In the month before, October 2017, the number of households on UC was 597,587, and over October to November, the number of households on UC increased by 25,852. Our models predict that the level of households claiming UC in October would correspond to about 7,953 people helped by food banks in November, which is about $6.7 \%$ of the 117,967 beneficiaries that actually received help in this month. Additionally, our model predicts that the observed change in households claiming UC would relate to 892 more beneficiaries in food banks in November. Thus, in total, our model predicts that about 7.5\% of the beneficiaries helped by food banks in November 2017 could be attributed to UC. 
Figure 3: The association between food parcel distribution and the roll-out of UC is greater in areas where food banks are located

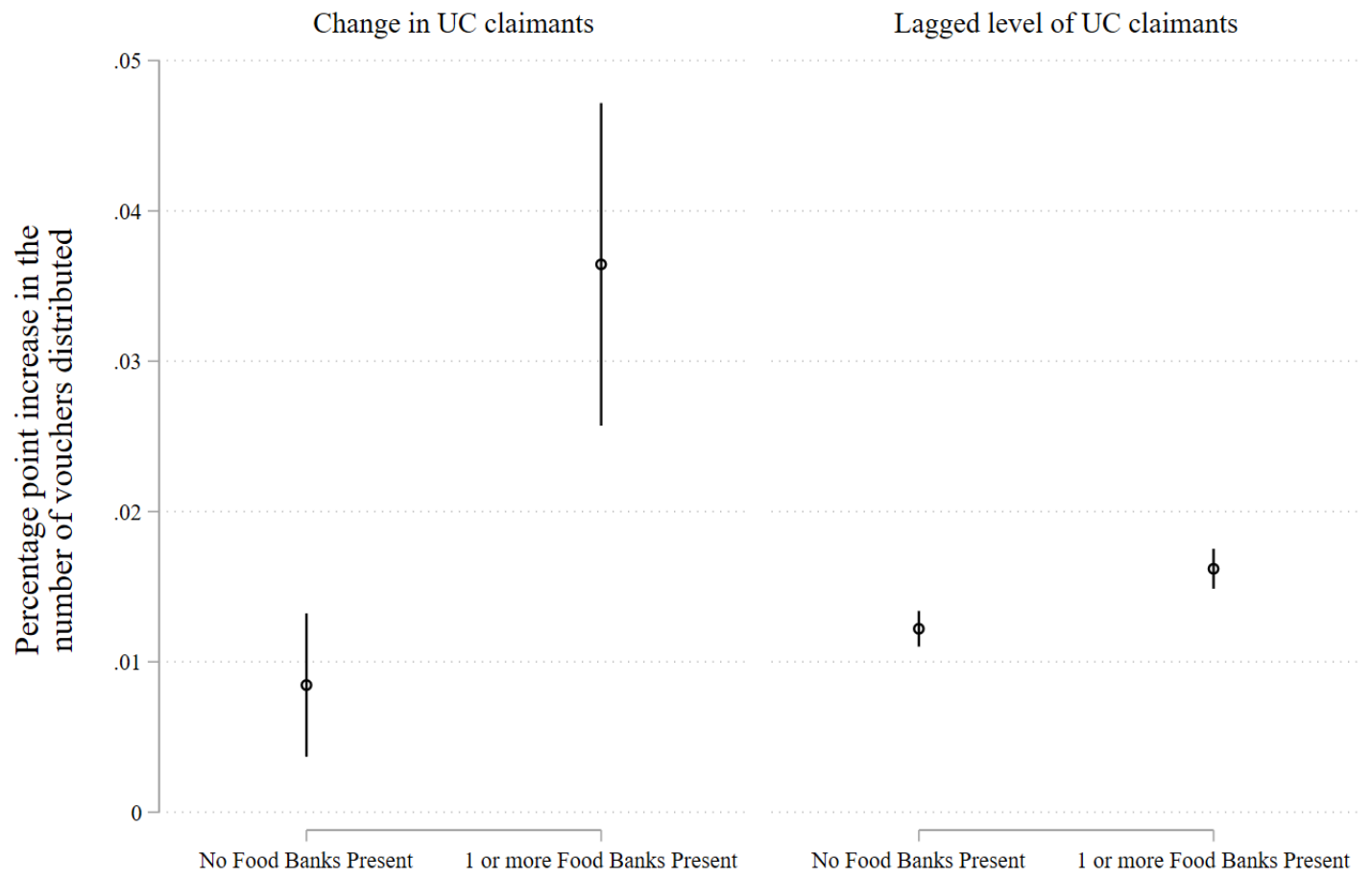

\section{SENSITIVITY ANALYSIS}

As a final sensitivity test, we also conduct a matching analysis which examines the average proportion of households receiving food parcels in the first 3 months following UC being introduced. Here we match on local authorities that have implemented UC compared to those who have not implemented UC and will not implement it over the follow 3 months. We also match them on a range of other covariates. We find that postcode districts implementing UC have higher food parcel distribution in the first 3 months after UC goes live than those matched postcode districts that did not (see Web Appendix 4 for full details).

\section{THE INTRODUCTION OF FULL SERVICE}

From 2016, Full Service UC began to be introduced in Jobcentres. Its roll out has been fairly slow, but by the end of 2017, it was active in 256 Jobcentres and a corresponding 992 postcode districts. Because claiming UC through Full Service has been associated with problems for claimants related to using the new online system, our next set of analyses examines whether, over and above the number of households claiming UC, we see an association between Full Service becoming active in postcode districts and food bank use. 
We again begin with a fixed effect analysis, where we examine the change in number of beneficiaries after Full Service went active across postcode districts (Table 3). We observe the proportion of households receiving food parcels increases by about $0.019 \%$ after Full Service goes active in postcode districts. Given that the average proportion of households receiving food parcels before Full Service roll out is $0.15 \%$, this represents a $10 \%$ increase. This association is independent of the number of people claiming UC and the number of beneficiaries in the month prior.

Table 3: Full service UC is positively associated with the proportion of households receiving food parcels

\begin{tabular}{|c|c|c|c|}
\hline \multirow[b]{2}{*}{ Covariates } & \multicolumn{3}{|c|}{$\begin{array}{l}\text { Percentage of food bank vouchers } \\
\text { redeemed per household } \\
(95 \% \mathrm{CI})\end{array}$} \\
\hline & (1) & (2) & (3) \\
\hline Full service is active in postcode district & $\begin{array}{l}0.019^{* *} \\
(0.0037)\end{array}$ & $\begin{array}{l}0.013^{* *} \\
(0.0040)\end{array}$ & $\underline{-}$ \\
\hline $\begin{array}{l}1 \% \text {-point increase in the proportion of } \\
\text { households on UC }\end{array}$ & 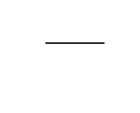 & $\begin{array}{l}0.011^{* *} \\
(0.0020)\end{array}$ & 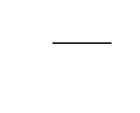 \\
\hline $\begin{array}{l}\text { Full service is active in postcode district } \\
\text { in the previous month }\end{array}$ & - & 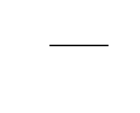 & $\begin{array}{l}0.015^{* *} \\
(0.0030)\end{array}$ \\
\hline $\begin{array}{l}1 \% \text {-point increase in the proportion of } \\
\text { households on UC in the previous month }\end{array}$ & 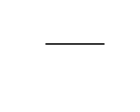 & 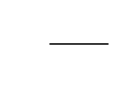 & $\begin{array}{l}0.0078^{*-+} \\
(0.0019)\end{array}$ \\
\hline Lagged measure of food parcel distribution & $\mathrm{N}$ & $\mathrm{N}$ & $\mathrm{Y}$ \\
\hline Seasonality & $\mathrm{Y}$ & $\mathrm{Y}$ & $\mathrm{Y}$ \\
\hline Linear time trend & $\mathrm{Y}$ & $\mathrm{Y}$ & $\mathrm{Y}$ \\
\hline Observations & 67709 & 67709 & 65104 \\
\hline
\end{tabular}

Notes: Standard errors are clustered for repeated observations within local authorities. Constant estimated but not reported. All models include postcode district fixed-effects. All models also control for the proportion of the working-age population that are job-seeking benefit claimants. ${ }^{*} p<0.05$, ${ }^{* *} p<0.01$

In light of findings from our previous analysis, which showed that the relationship between the number of people claiming UC and vouchers redeemed in food banks was stronger when food banks were present in the same postcode districts, we also test the interaction between Full Service going active, the presence of food banks, and the proportion of households redeeming food bank vouchers in postcode districts using our multi-level model.

The results of this three-way interaction are shown in Figure 4. It highlights that, where food banks are not located in the same postcode district, the relationship between households claiming UC and food bank use does not change when Full Service goes active. However, where food banks are present, there is a much stronger relationship between households claiming UC and food bank use when Full Service goes active (per 1 percentage point increase in households claiming UC, the percentage point increase in food bank vouchers is 0.033 (0.015 to 0.050) where Full Service is not active, but 0.082 percentage points (0.064 to 0.099) after Full Service 
Figure 4: The association between the roll-out of UC and food parcel distribution varies according to whether a food bank is present and whether UC is 'Full Active'

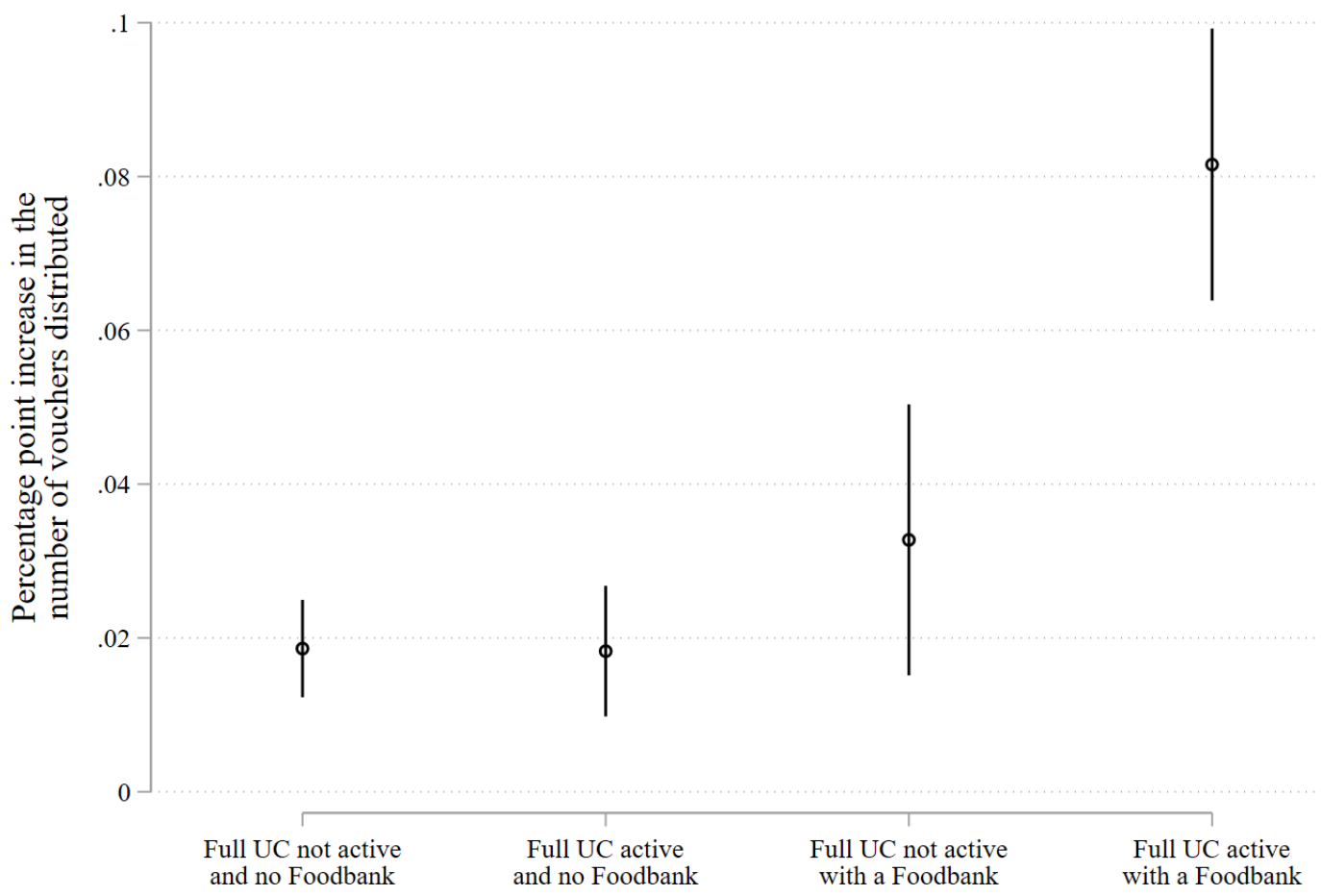

Notes: Point estimates represent the change in the proportion of households receiving food parcels association with a percentage point increase in the proportion of households on UC.

is active. We again estimate a matching model and find consistent results (see Web Appendix 5)

\section{DISCUSSION}

The roll out of UC embodies a major shift in the logic of social security. This reform attempts to simplify the benefit system by bringing six different targeted benefits into one overarching benefit, while making it more sensitive to the changing circumstances of those on low-incomes. In theory, this should make welfare easier to access and reduce the number of times claimants have to reapply for benefits as their circumstances change. However, in practice, many features of UC may cause hardship and ultimately make the benefit less responsive to the needs of claimants, especially those who are most vulnerable. First, UC incorporates the conditionalities that had previous only been applied to the unemployed and the disabled, whilst changing some of the structural features of how monies are paid and how people claim. Under UC, people are paid in arrears and, with the arrival, of the Full Service version of UC, are expected to apply online and regularly update their circumstances. Whilst unable to disentangle how 
each of these features of UC may relate to hardship, our analysis explores how the roll-out of UC relates to food bank usage, drawing on a uniquely detailed data set measuring food parcel distribution at the postcode district level. We find that the roll-out of UC was associated with rising food bank usage. Moreover, we find some evidence that moving to the digital version of UC (Full Service) has also increased the proportion of people relying on Trussell Trust food banks in the UK.

We found a particularly strong relationship was observed when Trussell Trust food banks were located in the same areas as UC claimants. One important implication of this finding is not, we argue, that UC has a weaker impact on economic hardship in areas without food banks, but rather the available data are unable to make visible the economic hardship created by UC in these areas. In other words, the hunger that may arise due to UC remains hidden. This might be because households are accessing food through independent food banks that operate in their area and for which no data are available through the Trussell Trust. But, it is also possible that people are simply going without because they do not have access to food aid in their area. Even more troubling is the frequently noted gap between the number of people who are food insecure and the number of people who use food banks. Put simply, even where households have access to food banks, only a small fraction of households that experience difficulty accessing food use food banks. Our results, then, are very likely underestimates of the impact of UC on hunger and, more broadly, food insecurity. Thus, the full extent to which the implementation of UC has resulted in households experiencing food insecurity is not fully captured by using Trussell Trust food bank data by itself.

The second implication of our findings concerns the broader trends in social security that the move to UC represents (Watts and Fitzpatrick, 2018). Our results indicate that any association between the roll-out of UC and the rise in food bank usage is not only 'teething problems' or administrative errors. UC seems to be more systematically related to the acceleration in the rise in hunger in the UK in recent years. Our analyses cannot single out one specific aspect of the reforms but, at the same time, it is unlikely to be due to only one feature of this new logic of social security. Extending conditionality, increasing the severity of the penalties for failing to adhere to these conditions, payment in arrears, and even the digitalization of the service have all potentially played some role in creating additional demand for food aid. More work will be need to unpack how these different elements are contributing to hardship.

While we use the best data currently available, there are also important limitations to our study. Area level analyses are susceptible to the ecological fallacy, that is, we simply do not know whether the people receiving food parcels from The Trussell Trust are indeed also receiving UC. Our results are, however, consistent with the rich body of qualitative work produced by both researchers and frontline services documenting the presence of UC recipients in food banks. The Trussell Trust data on food bank usage is less than ideal, for example, it does not cover food banks that are not part of their network (about $40 \%$ of food banks that operate in the UK), and it only records the volume of food parcels distributed rather than the number of unique users. And yet, The Trussell Trust remains, to our knowledge, the only source of longitudinal and harmonized data on food bank usage covering the UK. Furthermore, while we acknowledge that food bank use does not approximate the number of households experiencing 
food insecurity, regular monitoring of this problem has not been conducted in the UK. From 2019, a measure of household food insecurity will be included in the Family Resources Survey.

At the time of this analysis, the roll out of UC was still in its infancy. When completed, it is expected that around 8.5 million claimants will receive UC, $13 \%$ of the entire population. There will, of course, be challenges with implementing any large-scale change to social security systems. Our analysis, however, reveals more systemic problems. The association between UC and food bank usage actually gets stronger the longer UC has been active. This suggests, to quote the UK's 'Work and Pensions Committee', there might be 'fundamental flaw $[\mathrm{s}]$ in the benefit's design' (Keen et al., 2017), which could lead to a 'human and political catastrophe' (Field, 2017). The logic of UC may be 'theoretically impeccable' - in that it simplifies social security while incentivizing people to get into work - but it is also 'unforgiving', leaving too many economically precarious people struggling to make ends meet (Asthana, 2017).

Acknowledgments We would like to thank David Webster for his comments on an earlier version of this paper and for the time of the anonymous reviewers and the editors.

Aaron Reeves is an Associate Professor in the Department of Social Policy and Intervention at the University of Oxford, a Fellow of Green Templeton College, and a Visiting Senior Fellow in the International Inequalities Institute at the London School of Economics. He is a sociologist with interests in public health and political economy. His work involves examining the causes and consequences of social and economic inequity, primarily in Europe and North America.

Rachel Loopstra is Lecturer in Nutrition in the Department of Nutritional Sciences at King's College London. Her research focuses on household food insecurity and food bank use in highincome countries. Her work has been published in the BMJ, the Journal of Nutrition, and the Lancet Global Health. 


\section{REFERENCES}

Asthana, A. (2017) 'John Major Calls for Tory Review of “unfair” Universal Credit', The Guardian ( 8 October 2017).

Barnard, H. (2019) Where next for Universal Credit and Tackling Poverty?, York, Joseph Rowntree Foundation.

Brewer, M., Joyce, R., Waters, T. and Woods, J. (2019) Universal Credit and Its Impact on Household Incomes: The Long and Short of It, London, IFS.

Clair, A., Fledderjohann, J., Lalor, D. and Loopstra, R. (2019) 'The Housing Situations of Food Bank Users in Great Britain', Social Policy and Society, 1-19.

DWP (2010) Universal Credit: Welfare That Works, London, TSO.

DWP (2014a) Universal Credit Implementation: Findings from Local Authority Pilots, London, Department for Work and Pensions.

DWP (2014b) Evaluating the Impact of Universal Credit on the Labour Market in Live Service and the North West Expansion, London.

DWP (2018) Universal Credit: In-Work Progression Randomised Controlled Trial, London, Department for Work and Pensions.

Dwyer, P. and Wright, S. (2014) 'Universal Credit, Ubiquitous Conditionality and Its Implications for Social Citizenship', Journal of Poverty and Social Justice, 22, 27-35.

European Commission (2019) 'Eurostat.'

FAO (2019) Prevalence of Undernourishment, Rome, Italy, Food and Agriculture Organisation.

Field, F. (2017) Government Should Declare a 'Christmas Truce’ on Universal Credit, London, Commons Select Committee.

Fitzpatrick, S., Bramley, G. and Sosenko, F. (2018) Destitution in the UK 2018, York, Joseph Rowntree Foundation.

Foster, R., Adams, L., Stewart, G., Pinakova, P. and Newbold, P. (2017) The Transition from Tax Credits to Universal Credit - Qualitative and Quantitative Research with Claimants, London, DWP.

Foster, R., Adams, L., Svabaes, S., O’Driscoll, C. and Thomson, D. (2018) Universal Credit Full Service Survey, London, DWP. 
Garratt, E. (2017) 'Please Sir, I Want Some More: An Exploration of Repeat Foodbank Use', BMC Public Health, 17, 828.

Garratt, E. (2019) 'Food Insecurity in Europe: Who Is at Risk, and How Successful Are Social Benefits in Protecting against Food Insecurity?', Journal of Social Policy, 1-25.

Garthwaite, K. (2016) Hunger Pains: Life inside Foodbank Britain, Policy Press.

Geiger, B. B. (2017) 'Benefits Conditionality for Disabled People: Stylised Facts from a Review of International Evidence and Practice', Journal of Poverty and Social Justice, 25, 107-128.

Griggs, J. and Evans, M. (2010) Sanctions within Conditional Benefit Systems: A Review of Evidence, York, Joseph Rowntree Foundation.

Hills, J. (2014) Good Times, Bad Times: The Welfare Myth of Them and Us, Bristol, Policy Press.

Jitendra, A., Thorogood, E. and Hadfield-Spoor, M. (2017) Early Warnings: Universal Credit and Foodbanks, Salisbury, Trussell Trust.

Jitendra, A., Thorogood, E. and Hadfield-Spoor, M. (2018) Left behind: Is Universal Credit Truly Universal?, Salisbury, Trussell Trust.

Keen, R., Kennedy, S. and Wilson, W. (2017) ‘Universal Credit Roll-out: Autumn/Winter 2017’.

Kenworthy, L. (2010) ‘Labour Market Activation', The Oxford Handbook of the Welfare State.

Leete, L. and Bania, N. (2010) 'The Effect of Income Shocks on Food Insufficiency', Review of Economics of the Household, 8, 505-526.

Loopstra, R., Fledderjohann, J., Reeves, A. and Stuckler, D. (2018) 'Impact of Welfare Benefit Sanctioning on Food Insecurity: A Dynamic Cross-Area Study of Food Bank Usage in the UK', Journal of Social Policy, 1-21.

Loopstra, R., Reeves, A., McKee, M. and Stuckler, D. (2016) 'Food Insecurity and Social Protection in Europe: Quasi-Natural Experiment of Europe's Great Recessions 2004-2012', Preventive Medicine, 89, 44-50.

Loopstra, R., Reeves, A. and Stuckler, D. (2015) 'Rising Food Insecurity in Europe', The Lancet, $385,2041$.

Loopstra, R., Reeves, A. and Tarasuk, V. (2019) 'The Rise of Hunger among Low-Income Households: An Analysis of the Risks of Food Insecurity between 2004 and 2016 in a PopulationBased Study of UK Adults', J Epidemiol Community Health, jech-2018-211194. 
McArthur, D. and Reeves, A. (2019) 'The Rhetoric of Recessions: How British Newspapers Talk about the Poor When Unemployment Rises, 1896-2000': Sociology.

Millar, J. and Bennett, F. (2017) 'Universal Credit: Assumptions, Contradictions and Virtual Reality', Social Policy and Society, 16, 169-182.

NAO (2018) Rolling out Universal Credit, London, NAO.

Pierson, P. (1994) Dismantling the Welfare State?: Reagan, Thatcher, and the Politics of Retrenchment, Cambridge, Cambridge University Press.

Reeves, A. (2017) 'Does Sanctioning Disabled Claimants of Unemployment Insurance Increase Labour Market Inactivity? An Analysis of 346 British Local Authorities between 2009 and 2014', Journal of Poverty and Social Justice, 25, 129-146.

Reeves, A., Loopstra, R. and Stuckler, D. (2017) ‘The Growing Disconnect between Food Prices and Wages in Europe: Cross-National Analysis of Food Deprivation and Welfare Regimes in Twenty-One EU Countries, 2004-2012', Public Health Nutrition, 20, 1414-1422.

Taylor-Gooby, P. and Stoker, G. (2011) 'The Coalition Programme: A New Vision for Britain or Politics as Usual?', The Political Quarterly, 82, 4-15.

The Trussell Trust (2019) 'End of Year Stats', accessed at https://www.trusselltrust.org/newsand-blog/latest-stats/end-year-stats/.

Timmins, N. (2016) Universal Credit: From Disaster to Recovery?, London, Institute for Government.

Timmins, N. (2017) The Five Giants: A Biography of the Welfare State, London, HarperCollins. Trussell Trust (2020) 'What We Do'.

Watts, B. and Fitzpatrick, S. (2018) Welfare Conditionality, New York, Routledge.

Webster, D. (2019) Benefit Sanctions Statistics: Briefing - February 2019, Glasgow, University of Glasgow.

Welfare Conditionality (2018) Final Findings Report: Welfare Conditionality, 2013-2018, York, University of York.

Wunderlich, G. and Norwood, J. (2006) Panel to Review U.S. Department of Agriculture's Measurement of Food Insecurity and Hunger. Food Insecurity and Hunger in the United States: An Assessment of the Measure, and National Research Council (U.S.), Washington D.C., National Academies Press. 


\section{WeB APPENDIX}

Web Appendix 1: The roll out of UC by area characteristics

Web Appendix 2: Relationship between households claiming UC and receiving help from a food bank and the number of months UC has been active using a fixed-effects framework

Web Appendix 3: Multi-level model exploring the relationship between the level and change in households claiming UC in relation to the number of beneficiaries helped by food banks.

Web Appendix 4: Matching analysis comparing postcode districts that implemented UC with those that did not.

Web Appendix 5: Matching analysis of the introduction of Full Active UC 
Web Appendix 1: The roll out of UC by area characteristics

First we look at the socio-demographic characteristics of the areas in which UC was rolled out. We find that UC seems to have been introduced in areas with: (1) slightly higher than average proportion of the working-age population on benefits, (2) slightly higher than average populations, (3) slightly higher than average number of food banks, and (4) slightly more deprived than the average.

\begin{tabular}{ccccccc}
\hline \hline UC available & $\begin{array}{c}\text { Number } \\
\text { of } \\
\text { Postcode } \\
\text { districts }\end{array}$ & $\begin{array}{c}\text { Working } \\
\text { Age pop- } \\
\text { ulation } \\
\text { who are } \\
\text { claimants } \\
\text { (\%) }\end{array}$ & $\begin{array}{c}\text { Households Average } \\
\text { receiv- } \\
\text { ing food } \\
\text { vouchers } \\
\text { popula- } \\
\text { tion in } \\
\text { postcode } \\
\text { district }\end{array}$ & $\begin{array}{c}\text { Number } \\
\text { of food } \\
\text { banks }\end{array}$ & $\begin{array}{c}\text { Index of } \\
\text { Material }\end{array}$ & Deprivation ${ }^{1}$ \\
\hline Available in August 2015 & 1100 & 1.90 & 0.15 & 26634 & 0.53 & 12158 \\
\hline $\begin{array}{c}\text { Available in } \\
\text { September/October 2015 }\end{array}$ & 181 & 1.81 & 0.16 & 28572 & 0.64 & 12001 \\
\hline $\begin{array}{c}\text { Available in } \\
\text { November/December }\end{array}$ & 520 & 1.50 & 0.13 & 24745 & 0.47 & 14146 \\
\hline $\begin{array}{c}\text { 2015 } \\
\text { Available in }\end{array}$ & 483 & 1.63 & 0.13 & 21684 & 0.40 & 15237 \\
\hline January/March in 2016 & 231 & 1.48 & 0.10 & 13269 & 0.32 & 15271 \\
\hline $\begin{array}{c}\text { Available in } \\
\text { April/September 2016 }\end{array}$ & 62 & 1.66 & 0.08 & 1543 & 0 & 9079 \\
\hline $\begin{array}{c}\text { Available in October } \\
\text { 2016/December 2017 }\end{array}$ & 84 & 1.77 & 0.07 & 411 & 0 & 7872 \\
\hline $\begin{array}{c}\text { Not yet Active } \\
\text { All months }\end{array}$ & 2646 & 1.75 & 0.15 & 23053 & 0.46 & 13158 \\
\hline \hline
\end{tabular}

Notes: 1 - Lower average rank equals more deprived

Next we consider whether this may influence the speed at which new claimants come on UC. Here we find that more deprived parts of the country saw faster growth in the proportion of households on UC than less deprived parts of the country. 


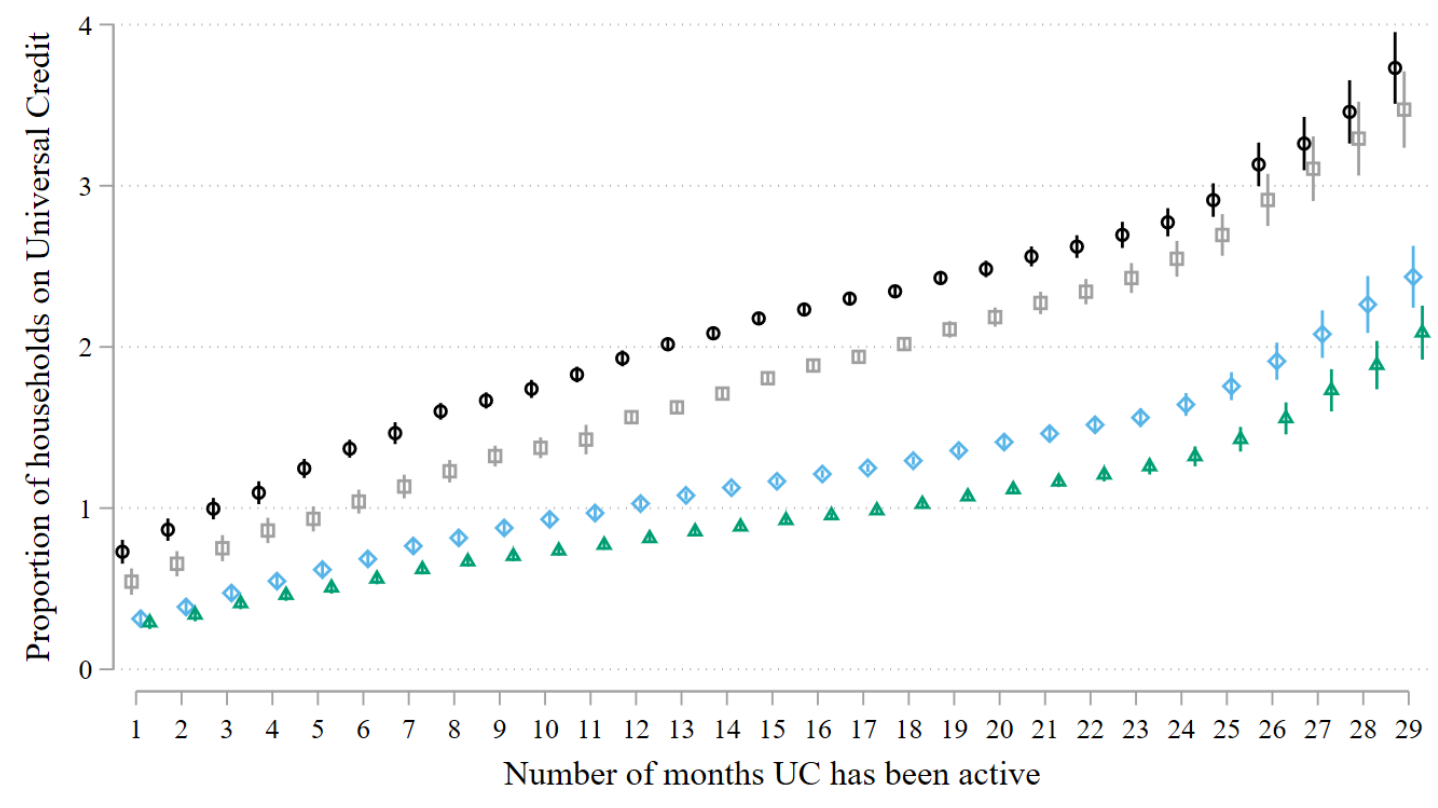

$\begin{array}{ll}\diamond \text { Most deprived quartile } & \square \text { 2nd quartile of deprivation } \\ \diamond \text { 3rd quartile of deprivation } & \Delta \text { Least deprived quartile }\end{array}$

However, when we consider the speed at which new claimants come on UC by the time at which their areas implemented UC we see very similar trajectories, especially in the first year. The one exception is the small number of postcode districts which have implemented UC since late 2016, which were initially higher and which have not increased much since. For the vast majority of postcode districts, however, the roll-out has happened at a very similar pace, suggesting the timing of the roll-out will not influence our results. 


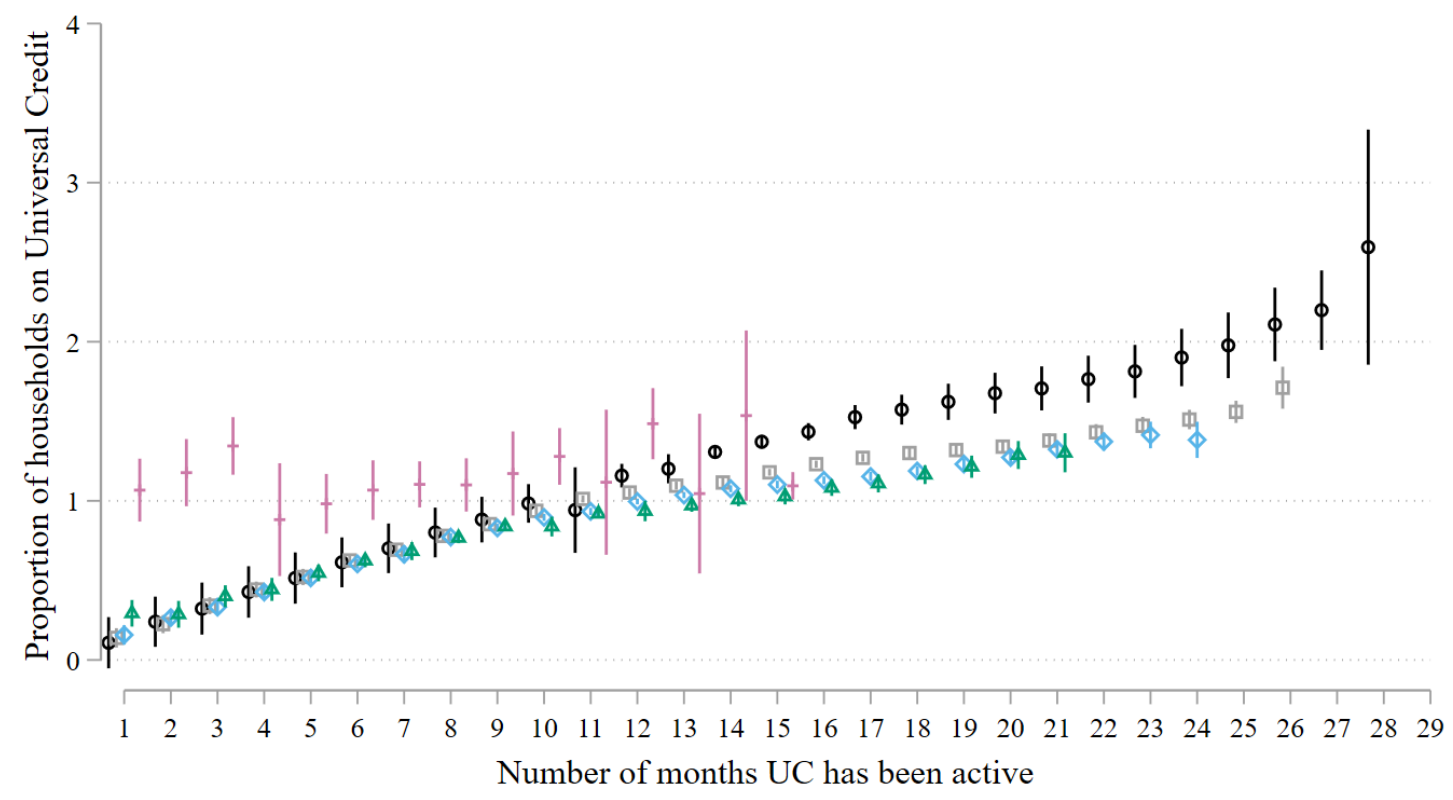

○ Active in September/October 2015 $\square$ Active in November/December $2015 \diamond$ Active in January/March in 2016

$\Delta$ Active in April/September 2016 + Active in October 2016/December 2017 
Web Appendix 2: Relationship between households claiming UC and receiving help from a food bank and the number of months UC has been active using a fixed-effects framework

\begin{tabular}{lc}
\hline \hline & $\begin{array}{c}\text { Percentage of food bank vouchers } \\
\text { redeemed per household } \\
(95 \% \mathrm{CI}) \\
(1)\end{array}$ \\
\hline 1\%-point increase in the proportion of households on UC & 0.0062 \\
& $(0.0027)$ \\
Number of months UC has been active & 0.00089 \\
& $(0.00013)$ \\
Increase in UC X number of months UC has been active & 0.00020 \\
& $(0.000073)$ \\
& 76,734 \\
Number of observations & \\
\hline Notes: Standard errors are clustered for repeated observations within local authorities. Constant estimated but \\
not reported. All models include postcode district fixed-effects. All models also control for the proportion of \\
the working-age population that are job-seeking benefit claimants. Y = model controls for that variable.
\end{tabular}


Web Appendix 3: Multi-level model exploring the relationship between the level and change in households claiming UC in relation to the number of beneficiaries helped by food banks.

The models in table 2 and this web appendix are exactly the same except for two changes. First, our dependent variable in this model is the number of beneficiaries instead of the number parcels distributed for every 100 households (see Table 2). Second, the main predictor variable is now the number of UC claimants as opposed to the number of UC claimants per 100 households.

Table 2: Multi-level model exploring the relationship between the level and change in households claiming UC in relation to the number of households using food banks.

\begin{tabular}{lcc}
\hline \hline & \multicolumn{2}{c}{$\begin{array}{c}\text { Percentage of food bank vouchers } \\
\text { redeemed per household } \\
\text { (95\% CI) }\end{array}$} \\
Covariates & $(1)$ & $(2)$ \\
\hline $\begin{array}{l}\text { Per household increase in households } \\
\text { claiming UC in one month prior }\end{array}$ & 0.035 & 0.00071 \\
Per additional household & $(0.0067)$ & $(0.0099)$ \\
claiming from the month prior & 0.013 & 0.0040 \\
& $(0.00074)$ & $(0.0011)$ \\
Food bank in postcode district & 10.67 & 8.40 \\
& $(0.32)$ & $(0.35)$ \\
Households claiming UC X food bank present & & 0.062 \\
& - & $(0.013)$ \\
Change in households claiming UC X food & & 0.014 \\
bank present & - & $(0.0012)$ \\
Lagged measure of food parcel distribution & & $\mathrm{Y}$ \\
Seasonality & $\mathrm{Y}$ & $\mathrm{Y}$ \\
Linear time trend & $\mathrm{Y}$ & $\mathrm{Y}$ \\
Region identifiers & $\mathrm{Y}$ & $\mathrm{Y}$ \\
\hline Postcode district-months & $\mathrm{Y}$ & 68,376 \\
\hline \hline
\end{tabular}

Notes: Standard errors are clustered for repeated observations within local authorities. Constant estimated but not reported. We estimate multi-level models with random intercepts. All models also control for population size and the proportion of the working-age population that are job-seeking benefit claimants. $\mathrm{Y}=$ model controls for that variable. 
Web Appendix 4: Matching analysis comparing postcode districts that implemented UC with those that did not.

First we create a sub-sample of the postcode districts. This sub-sample contains postcode districts which implemented UC and also includes observations from postcode districts that have not (or have not yet) implemented UC. To be in this group, postcode districts should not have implemented UC in January 2017, for example, and will not implement UC in the 2 months following month January 2017. This is illustrated in the table below. Area 1 would be included in our sample because it is an area that introduces UC. Area 2 would not be included in our matching sample because it introduces UC at the end of the 3 month window. Area 3 would be included because it does not introduce UC in the 3 month window.

\begin{tabular}{|l|c|c|c|c|}
\hline & December 2016 & January 2017 & February 2017 & March 2017 \\
\hline Area 1 & & $\mathrm{X}$ & $\mathrm{X}$ & $\mathrm{X}$ \\
\hline Area 2 & & & & $\mathrm{X}$ \\
\hline Area 3 & & & & \\
\hline
\end{tabular}

Next, once we have created this sample of postcode districts that have and have not introduced UC, we estimate a matching model using coarsened exact matching. Coarsened Exact Matching $(\mathrm{CEM})$ is a partial matching procedure. CEM splits all variables into bins or categories. CEM uses an algorithm to determine an appropriate number of bins or categories for linear or continuous variables. We match respondents on the following variables: the proportion of households receiving a food voucher in the previous month, the month, whether a food bank is present in the area, the size of the population, the proportion of people claiming JSA or UC in the previous month, and the region of the country in which the postcode district is located.

Adding all these variables together creates 2532 different possible combinations (or strata) and the CEM algorithm seeks to match the postcode districts with UC to those without UC. Only 345 strata have matched individuals. It is possible to have more than one match in each strata and so the matching is weighted to reflect the uneven distribution of the data across these strata. CEM is usually assessed using a global fit statistic $\zeta_{1}$ (or $L 1$ ). This fit statistic tells us how imbalanced the data sets are before the matching procedure $(1=$ completely separable or no-overlap while $0=$ perfectly balanced).

In our analysis, before the matching procedure, $\zeta_{1}$ is 0.937 while after the matching procedure $\zeta_{1}$ has fallen to 0.824 , which we regard as a significant improvement. If we look at the differences between specific variables we can see that on all of the variables the matching has been somewhat successful, removing some of the differences between the distribution of these variables (e.g., the proportion of vouchers distributed in the previous month and population). On most variables the degree of imbalance has been almost completely eliminated (e.g., month, whether a food bank was present, region). The matching is not perfect, of course, but CEM is by definition an improvement over the imbalance observed in the raw data. 
Web Table 4a: Balance between key covariates before and after matching

\begin{tabular}{lccc}
\hline Variable & $\begin{array}{c}\text { Variable specific } \\
\text { measure of } \\
\text { imbalance }\left(\zeta_{x}\right)\end{array}$ & $\begin{array}{c}\text { Difference in } \\
\text { means before } \\
\text { matching }\end{array}$ & $\begin{array}{c}\text { Difference in } \\
\text { means after } \\
\text { matching }\end{array}$ \\
\hline Vouchers distributed in previous month & 0.2674 & 0.054 & 0.017 \\
Month & 0.3980 & -1.487 & $<0.001$ \\
Food bank present & 0.1670 & 0.245 & $<0.001$ \\
Population & 0.4246 & 12067 & 1071 \\
Claimants in the previous month & 0.2046 & 0.0372 & 0.0097 \\
Region & 0.2724 & 1.272 & $<0.001$ \\
\hline
\end{tabular}

We then estimate the regression model with the matched data. The predictor is whether UC is active and the dependent variable is the proportion of households receiving UC in the first 3 months following UC implementation. We find more households receive UC in the 3 months following introduction than in otherwise similar postcode districts.

Web Figure 4b: Results from matching analysis.

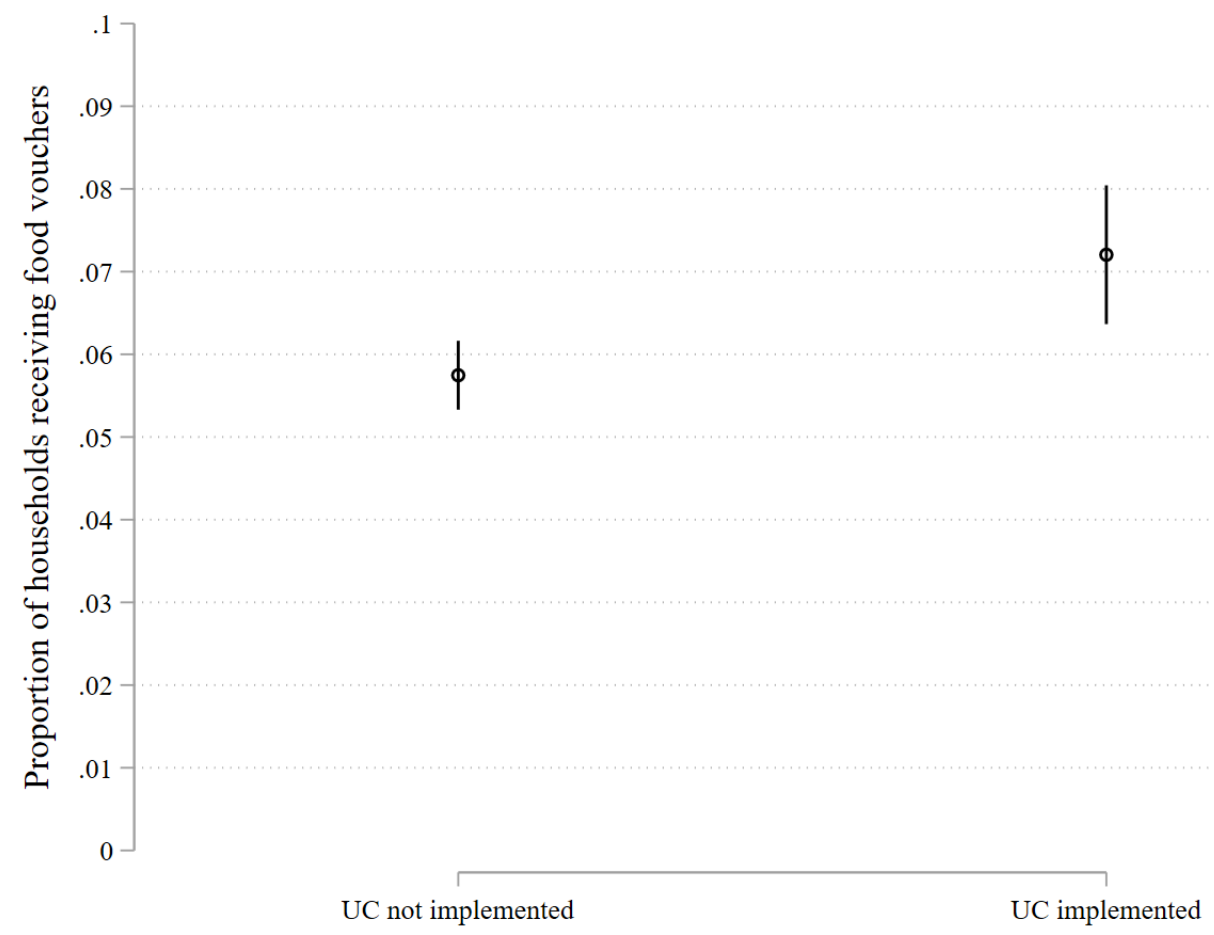


Web Appendix 5: Matching analysis of the introduction of Full Active UC

We use the same matching procedure described in Web Appendix 4, with two important differences. The first change is our intervention comparison is across Full Active and Not Full Active areas. The second change is we now also match on the proportion of households receiving UC, which simultaneously allows us to match on whether UC is active or not and, given that it is active, how far the roll-out has occurred.

Adding all these variables together creates 29,778 different possible combinations (or strata) and the CEM algorithm seeks to match the postcode districts with UC to those without UC. Only 215 strata have matched individuals. It is possible to have more than one match in each strata and so the matching is weighted to reflect the uneven distribution of the data across these strata. CEM is usually assessed using a global fit statistic $\zeta_{1}$ (or $L 1$ ). This fit statistic tells us how imbalanced the data sets are before the matching procedure $(1=$ completely separable or no-overlap while 0 = perfectly balanced).

In our analysis, before the matching procedure, $\zeta_{1}$ is 0.998 while after the matching procedure $\zeta_{1}$ has fallen to 0.944 . This is only a modest improvement and so we look in more detail at the imbalance across these variables. On many of the variables we see the degree of imbalance has been reduced to almost zero (e.g., the proportion of vouchers distributed in the previous month, month, whether a food bank was present, region, and the proportion of people claiming benefits). There are two variables where the imbalance is still higher than would be ideal (e.g., the proportion of households receiving UC and population). The matching is not perfect, of course, but CEM is by definition an improvement over the imbalance observed in the raw data.

Web Table 5a: Balance between key covariates before and after matching

\begin{tabular}{lccc}
\hline Variable & $\begin{array}{c}\text { Variable specific } \\
\text { measure of } \\
\text { imbalance }\left(\zeta_{x}\right)\end{array}$ & $\begin{array}{c}\text { Difference in } \\
\text { means before } \\
\text { matching }\end{array}$ & $\begin{array}{c}\text { Difference in } \\
\text { means after } \\
\text { matching }\end{array}$ \\
\hline Vouchers distributed in previous month & 0.0777 & 0.023 & -0.0137 \\
Month & 0.5720 & 7.729 & $<0.001$ \\
Food bank present & 0.0244 & 0.0444 & $<0.001$ \\
Population & 0.0805 & -608.89 & -173.52 \\
Claimants in the previous month & 0.2552 & 0.0496 & -0.0397 \\
Region & 0.1466 & 0.0515 & $<0.001$ \\
Proportion of households receiving UC & 0.2040 & 0.4155 & 0.0096 \\
\hline
\end{tabular}

We then estimate the regression model with the matched data. The predictor is whether UC is full active or not and the dependent variable is the proportion of households receiving UC in the first 3 months following UC implementation. We find more households receive UC in the 3 months following introduction than in otherwise similar postcode districts. 
Web Figure 5b: Results from matching analysis.
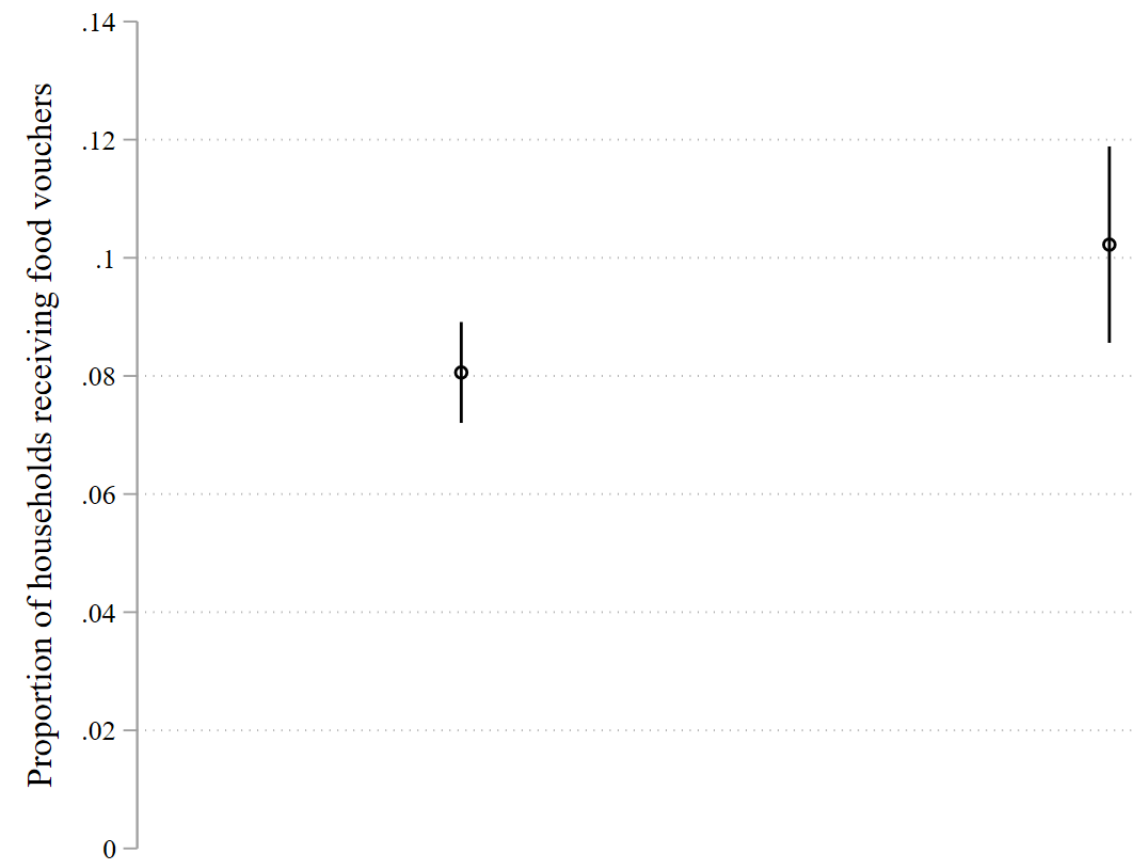